\title{
Rice production constraints and 'new' challenges for South Asian smallholders: insights into de facto research priorities
}

Adam John ${ }^{1,2^{*}}$ and Matthew Fielding ${ }^{2,3}$

\begin{abstract}
Background: The international community and national agricultural research systems (NARS) recognize the importance of supporting smallholders in order to reduce poverty and promote the food security status of some of the most vulnerable groups in the world. South Asia has the largest food-insecure population in the world, and in several farming systems in the region, rice is the most important staple crop. This study examined the extent to which agricultural research has prioritized the greatest factors that constrain smallholder productivity in those farming systems. It also explored the degree to which research has connected production constraints and environmental challenges faced by rice smallholders.

Results: Estimated congruency ratios suggested that peer-reviewed research has been heavily skewed towards abiotic production constraints. Meanwhile, socio-economic production constraints had received relatively little attention from the research community, even though socio-economic constraints account for more than $22 \%$ of rice yield losses in the South Asian farming systems examined. Furthermore, although research publications have tended to concentrate on the most important rice production constraints and linked those constraints to challenges identified by environmental disciplines, there are many medium and small production constraints which have received little research attention. This is despite the fact that the sum of these less severe constraints represents the largest contribution to total rice yield losses.

Conclusions: While national and international research bodies are well aware of the challenges smallholders face, there seems to be a lack of coordination in setting research priorities, since there are many areas, particularly in the social sciences field, which are not receiving the research attention that they warrant, when compared to the opportunity improvements in this sector could provide-as demonstrated in this study. This suggests that steps need to be taken in providing the research community with incentives and support in understanding these 'needs' to increase the impact of their research. Increasing the level of accountability of research institutions to smallholders' and rural populations' needs and promoting participatory farmer-focused research may help in improving research coordination and improving livelihoods by reducing poverty.
\end{abstract}

Keywords: Production constraints, Rice, Agricultural research, Food security, Smallholders, South Asia

\footnotetext{
*Correspondence: adam.dr.john@hotmail.com

${ }^{1}$ Institute of Agricultural and Food Policy Studies, Universiti Putra Malaysia,

Putra Infoport, Jalan Kajang-Puchong, Serdang, Selangor 43400, Malaysia

${ }^{2}$ Stockholm Environment Institute, Linnégatan 87 D, Stockholm 115 23,

Sweden

Full list of author information is available at the end of the article
}

\section{Biomed Central}

(c) 2014 John and Fielding; licensee BioMed Central Ltd. This is an Open Access article distributed under the terms of the Creative Commons Attribution License (http://creativecommons.org/licenses/by/4.0), which permits unrestricted use, distribution, and reproduction in any medium, provided the original work is properly credited. The Creative Commons Public Domain Dedication waiver (http://creativecommons.org/publicdomain/zero/1.0/) applies to the data made available in this article, unless otherwise stated. 


\section{Background}

Smallholders are a vital part of the international agricultural community, but they have historically been neglected in most national and international forums. Supporting smallholders has been a strategic priority for the International Fund for Agricultural Development (IFAD) since it was set up in the early 1970s in response to a food crisis, and now a broader range of international organizations say they are putting smallholders at the top of their agenda [1]. An example of this increased attention is the UN's establishment of 2014 as the international year of family farming. The Consultative Group on International Agricultural Research (CGIAR) reevaluated its strategy in 2008 to focus its research more towards poor farmers' needs [2]. There has even been a growth in smallholder research interest from non-traditional private donors, including the Syngenta Foundation for Sustainable Agriculture and the Yara Foundation [3]. In the political arena, promoting sustainable smallholder agriculture was on the agenda of the G20 meeting in 2012, which emphasized the need for greater market participation to complement productivity gains [4]. As a high-level panel noted in 2013 [1], there has been a vicious circle of poor research and extension for low-income farmers, and it needs to be broken.

The study examines where research relevant to production constraints is focused, and how that fits with where yield losses are known to take place. The study looks specifically at research on rice in South Asia, since the region is home to one of the world's largest food-insecure populations, and rice is the most important crop there. The study also aims to identify whether research has made connections between different areas of production constraints and environmental concerns which are recognized as new challenges for smallholders.

This article begins by providing an overview of linkages between smallholders, food security, and agricultural research support for smallholders. We then describe the methodology used to quantify research and how network analysis was used to show interactions within different research fields. We then present and discuss the results and conclude with some implications of the study and its relevance to agricultural research policy.

\section{Supporting smallholders promotes global food security}

Defining what constitutes a smallholder is not merely concerned with setting a threshold in terms of hectares. The High Level Panel of Experts highlights that a smallholding is 'small' in the sense that it has scarce resources which are barely enough for a smallholder to satisfy their basic needs [1]. For the majority of smallholders, especially those in South Asia, the threshold is far below 2 ha. There are an estimated 500 million smallholder farms around the world, which employ about 2.5 billion people either on a full-time or part-time basis [5]. In South Asia, $75 \%$ of farmers are smallholders [6]. In India, the number of smallholdings rose from 70 million in 19701971 to 121 million in 2000-2001, which has put downward pressure on farm size, shrinking the average smallholding from 2.3 to 1.32 ha in the same period [7]. Women commonly take responsibility for producing food crops, particularly where smallholder farms produce both food for the household and cash crops [8]. Smallholders produce the bulk of food in developing countries, and their contribution is growing [9]. For instance, smallholders produce $70 \%$ of the food supply in Africa [10], and $80 \%$ of the food consumed in sub-Saharan Africa and Asia is produced by smallholders [11].

Paradoxically, although smallholders play a significant role in global food production, they are net food buyers [12] and make up the majority of the world's undernourished and poor population [1,13-16]. This is why supporting smallholder agriculture is recognized as playing a major role in reducing hunger and malnutrition. Lipton [17] found no examples of agricultural development that alleviated poverty without improving smallholder productivity. A review by the UN Food and Agricultural Organization (FAO) and the World Bank [18] concluded that international development goals such as halving hunger and poverty would not be achieved without policies that prioritize improving the productivity of small farms. The Sustainable Development Network concluded that millennium development goal 1 , to eradicate extreme poverty and hunger, would not be achieved without focusing on poor farmers in rural areas [14].

It is important to acknowledge that increasing smallholder productivity not only improves smallholders' food security but also global food security because they produce such a large share of developing countries' food supplies. Its importance for global food security is expected to rise because of a growing world population [1]. One study [19] estimated that more than $50 \%$ of the food needed to feed the projected nine billion world population in 2050 will be produced by smallholders. In terms of poverty reduction, supporting smallholder agriculture is expected to have a greater impact in sub-Saharan Africa and South Asia, as developing non-agricultural sectors are seen as more important for poverty reduction in East Asia and Latin America [20].

\section{Agricultural research for smallholders}

The massive agricultural research and technology transfer effort of the 1960s and 1970s, often referred to as the 'green revolution', led to dramatic increases in agricultural productivity. Smallholders in developing countries, especially in Asia and Latin America, benefited substantially from these advances in agricultural research as well as from strong extension services [21]. However, many 
of these production gains resulted in environmental degradation [5]. The current food security challenge is as great as 40 years ago but now with the need to address sustainability and deal with climate change. Not only does food production need to increase substantially in order to meet future demand, but with climate change, there is considerable concern that we may even struggle to sustain current food production levels. For instance, studies have outlined how agricultural production is predicted to decline in developing countries [22,23]; one estimated that the decline could be as much as $20 \%$ [14]. Therefore, agricultural productivity needs to rise both to meet new demand and to offset expected climate-related yield losses in some regions [14].

International bodies have outlined that research to benefit smallholders and promote food security needs to tackle both traditional and new challenges. Traditional areas of interest include strengthening land tenure rights $[5,24]$ and extension services [5,14], improving infrastructure [24], making smallholder agriculture more marketoriented $[3,5,24]$, and improving smallholders' access to inputs $[2,5,14,24]$. Newer areas of focus include adaptation to climate change $[3,5,25]$, biodiversity and natural resource management $[5,25]$, crop diversification and nutrition security $[1,2,25,26]$, multifunctional agriculture [5], sustainable intensification [5], and promoting food crops [1,2,24,26,27].

Although smallholders share common constraints and challenges, such as those mentioned above, it is important to recognize that they are not a homogeneous group nor are they equally affected by common challenges. For instance, in East Africa, smallholders in hotter, low-lying areas are predicted to see their yields decline due to climate change, whereas smallholders located at higher elevations and lower average temperatures may even see their yields rise in the future because of climate change [28]. In addition, a study focusing on the Sudanian and Sahelian savannahs of West Africa showed that the impact of temperature and rainfall due to climate change is expected to have very different consequences for the regions of West African countries located in the two savannahs [29]. For instance, their results suggested that increases in temperature would have a more adverse effect on millet and sorghum grown in the southern part of Senegal than in the north of the country. Such examples support the need to consider the heterogeneity of smallholders when making policy decisions, which was stressed in a recent FAO report [4].

\section{Agricultural research in South Asia}

National agricultural research systems (NARS) such as India's were some of the first countries in the developing world to develop strong relationships with international agricultural research centers (IARC), such as the International Rice Research Institute (IRRI) [30]. This may be partly due to the fact that South Asian NARS were established earlier than in most other developing countries. For example, the Indian Centre of Agricultural Research (ICAR) was formed in 1929, [31]. Agricultural research in South Asia has traditionally largely focused on productivity-enhancing technologies for staple grains such as rice and wheat, which has been successful at meeting South Asian countries' food production goals [32]. For instance, India has managed to increase its production of food grains fourfold since the 1960s [7]. This was achieved through partnerships between the likes of IRRI and ICAR in India whereby the former provided new high-yielding gene lines for the South Asian NARS to develop into end products for their domestic farmers [30].

It has been argued, however, that the focus on rice and wheat in irrigated and rainfed favorable regions may have come at the expense of other important food crops as well as less favorable, resource-poor regions [32]. This has been followed by questions being raised about whether different groups of South Asians benefited disproportionately from the agricultural developments of the green revolution. A CGIAR science council assessment [32] found that while overall, agricultural research had been very effective at reducing poverty, sometimes richer South Asian households benefited more than poorer ones, widening income gaps. The latter study also raised the issue of 'hidden hunger'-micronutrient deficiencies which were not satisfactorily addressed by the green revolution breakthroughs.

Other concerns have been raised as well about the impact of agricultural research in South Asia. A recent report by the Asia-Pacific Association of Agricultural Research Institutions (APAARI) and the International Food Policy Research Institute (IFPRI) concluded that, with the exception of India, agricultural research for development in South Asia has generally been neglected, with only a slight improvement since the 2008 food crisis [6]. The report also highlights that public sector investments in agricultural research in Bangladesh and Nepal in 1996-2009 were proportionally lower than in India and other developing countries, such as Brazil. What is more, the rate of growth in agricultural research fell between 1996 and 2009 in Bangladesh, Nepal, and India, though it has risen again in India since 2006. Agricultural growth in South Asia has also been weaker in recent decades. The APAARI and IFPRI assessment [6] attributes the South Asian NARS' limited impact on weak institutional capacities and irregular funding.

The CGIAR assessment [32] finds that food grain productivity should continue to be prioritized but argues that new efforts must also encompass natural resource management and sustainability. It also notes that unlike 
the green revolution technologies, which were bestsuited to areas with favorable cultivating conditions, research now needs to focus on increasing productivity in least favorable areas (LFAs) as well. The APAARI and IFPRI report [6] makes similar points and suggests that the public sector will play the dominant role in supporting LFAs, because the private sector shows little interest in these regions.

The APAARI and IFPRI assessment [6] also finds that agricultural research for development will have to triple or quadruple in the coming years for South Asia to achieve its food production goals. It says the participation of stakeholders in agricultural research is fundamental to achieving agricultural development goals, so farmer-participatory focused research should be a top priority for South Asia. Expanding on research priorities to cover areas such as natural resource management is also seen as important by South Asian NARs. ICAR's 'Vision 2030' [7] sees halting land degradation and rehabilitating degraded land and water resources in India as a top research priority. Promoting agricultural diversification and involving social sciences more in agricultural research challenges are other priorities raised by ICAR. Ultimately, supporting smallholders must remain a key component of agricultural research in South Asia [6,7].

\section{Methods}

\section{Farming systems approach}

Farming systems analysis is a conceptual framework which considers the heterogeneity of smallholders and is useful for designing appropriate agricultural development strategies. It defines the interactions between a household, its activities, and the resource base as a farm system, where the biophysical, socio-economic, and human elements are interdependent $[18,33]$. The FAO and World Bank [18] have further defined a population of individual farm systems with broadly similar characteristics and constraints as a farming system. They identified eight broad farming system types covering the developing world and categorized these into 63 farming systems covering Latin America, sub-Saharan Africa, South Asia, and East Asia. Despite the amount of detail in their farming systems analysis, they acknowledge that there is some degree of heterogeneity within each of the specified farming systems, and the boundaries between farming systems across geographic areas can be quite loose. Nevertheless, a farming systems approach can provide an insightful take on the idiosyncratic nature of smallholder agriculture.

A 2008 study [33] identified the most food-insecure and drought-prone among the 63 farming systems in order to demonstrate where agricultural research should be prioritized. The authors identified 15 farming systems with more than 2.5 million stunted children each, and they detected the 13 major food crops that these vulnerable farming systems largely relied on. The two farming systems with the highest amount of stunted children were the South Asian rice-wheat (28.3 million) and rainfed mixed (24.5 million) farming systems. In fact, five of the top ten farming systems with the highest number of stunted children were in South Asia.

The International Maize and Wheat Improvement Center (CIMMYT) [34] interviewed panelists with regional expertise for 12 of the 15 food-insecure and droughtprone farming systems highlighted by [33] to identify the top ten production constraints for maize cultivation in each of the farming systems. While droughts were shown to be a common constraint for all of the farming systems in the [33] study, due to the heterogeneity that exists between farming systems, CIMMYT wanted to exploit the tacit knowledge of maize research and extension experts. The panel of experts assessed the relative importance of several groups of production constraints, which could be categorized into four groups: biotic, abiotic, crop management, and socio-economic constraints. A 2010 study [35] used the same methodology but expanded the analysis by including six other food crops important to the 13 of the 15 food-insecure farming systems identified by [33]: wheat, rice, sorghum, cowpea, chickpea, and cassava. In the case of the five South Asian farming systems, the authors identified rice as the most important staple crop in four of the five systems, with the exception being the dry rainfed farming system, where sorghum is the most important staple grown in terms of total area harvested.

Like the CIMMYT study, [35] was able to identify the major production constraints for the six food crops in 13 farming systems. Furthermore, the authors indicated the cost of each constraint in terms of its contribution to the yield gap between the highest achieved crop yield and the average crop yield for each food crop analyzed in each of the food-insecure farming systems. What is striking about the two studies $[34,35]$ is the diversity of constraints and their relative importance for each crop in each farming system. A shortcoming of these studies, which [35] acknowledges, is that while studies tend to assume that constraints are additive, in practice, many constraints interact and should be seen as multiplicative. For instance, improving soil fertility may also improve water availability (due to less runoff), so the impact on increased yields may be amplified. Nevertheless, the studies illustrate the extent of heterogeneity in smallholder agriculture and help confirm why a farming systems approach is useful for setting priorities in smallholder agricultural research and policy.

This study focuses on the production constraints of four of the food-insecure South Asian farming systems described in [35] where rice is the dominant crop: ricewheat, rainfed mixed, rice, and highland mixed. The [35] 
analysis also identified the top ten constraints to rice production, which account for only about half of the total rice yield losses in the South Asian farming systems. This study extends on [35] by including the top 24 rice production constraints that were identified by the authors in [35], which they did not publish but made available for this study. The advantage of including the top 24 production constraints is that together, they cover $80 \%-90 \%$ of total rice yield losses, providing a more holistic perspective.

As noted in the introduction, agricultural research today needs to focus not only on the traditional production constraints, but also on 'new' constraints, most of which may be seen as environmental challenges, such as climate change, natural resource management, ecosystem services, biodiversity, and sustainability. This study considers those constraints, which are being given more attention by global development agencies, as well as two other key factors also prioritized by those agencies: diversification and food security.

\section{Quantifying agricultural research}

Measuring scientific output has its own field of study, called scientometrics, which provides various types of quantitative methods based on bibliometric and patent indicators [36]. This study uses publication analysis, which can be used as an indicator of scientific activity [37]. We perform a straight publication count of peerreviewed journal articles cited by Scopus which include the keyword criteria captured by queries performed in the advanced search options of Scopus. There are several abstract and citation databases of peer-reviewed literature to choose from, but Scopus is the largest, and it covers a broad spectrum of academic disciplines in the physical and social sciences [38] which is why it was used in this study. A weakness of Scopus is that its coverage of publications only starts in 1995, but the period covered by this study begins in 1997, the year after the Rome Declaration for World Food Security.

We counted the journal articles published between 1997 and 15 February 2014 that had focused on rice production constraints for South Asian farming systems as outlined in [35] as well as the 'new' challenges for smallholders as specified in many international development reports. Keywords for the search were derived from the description of production constraints in [35]. The keywords used to represent each production constraint, along with the rice production constraints descriptions, can be found in Additional file 1: Table S4. To be included in the count, the publication had to have the keywords in its title or in the publication keywords. Since we are only interested in publications focusing on rice, the word 'rice' was also specified in the Scopus queries as being present in the publications' title or as a keyword.
It is important to recognize that this is not a definitive publication search. While Scopus is the most extensive citation-based database, there will naturally be other quality publications which were not captured in the search. What is more, the specification of the keywords puts further restrictions on the publication selection process. There will surely be publications which are perhaps relevant to South Asian rice smallholders but which were not captured in the publication search because they used different keywords. However, the inclusion of too many keywords would have diluted the relevance of the captured publications, so a trade-off had to be made.

The final criterion of the selection of the publications was the location. South Asian farming systems as defined in [18] cover seven countries: India, Pakistan, Bangladesh, Sri Lanka, Nepal, Bhutan, and Afghanistan, therefore the Scopus queries were confined to these countries. The term 'smallholder' was not included in the queries; this is because it was found that the majority of journal articles focusing on rice production constraints in South Asia did not use the term, even though it was evident from the abstracts that the articles focused on smallholders. This may be explained by the fact that the majority of farmers in South Asia are smallholders, so it may seem redundant to use the term when discussing South Asian farmers. An example of one of the queries used in Scopus is given in the top cell of Additional file 1: Table S4. The entire list of journal articles retrieved from the Scopus search is stored in the spreadsheet in Additional file 2.

To clearly represent the results, congruency ratios were estimated for each constraint. A congruency ratio is a common way of assessing the efficiency of research resource allocation [39]. In this study, the measure is the ratio between the percentage of journal articles which focused on the constraint and the role of the constraint as a percentage of total yield losses. A ratio score of more than 1 may suggest that there is a surplus of articles which have focused on the particular constraint, whereas a ratio of less than 1 may suggest the contrary.

\section{Network analysis}

Network analysis or social network analysis was originally developed in the sociology field in the 1970s [40]. Other disciplines in the social sciences as well as the physical sciences such as biology have since incorporated network analysis as an empirical tool. Network analysis is primarily interested in representing relationships between actors using graphs. Interactions between pairs of actors or nodes are represented in the graph with a line, called an edge. The characteristics of a network graph can be described using global graph metrics or individual actor properties [41]. The former is used to describe 
the network as a whole, while the latter provides insights into the influence or connectedness of the actors. For the purposes of this study, the network analysis is restricted to describing the actor properties of the network which represent rice production constraints.

Centrality measures are a common way of capturing the status of actor properties. There are several centrality measures whose application depends on the purpose of the study; however, their binding characteristic is that they all quantify how central each actor is within a network. For instance, closeness centrality measures how long it takes an actor to spread information to the other actors within the network whereas 'betweenness' centrality measures how many times an actor connects two other actors along the shortest path in the network [42]. Degree centrality is perhaps the most straightforward centrality measure which is an actor's sum of interactions with other actors within the network. Degree centrality suffices for our study, as we are simply interested in identifying the diversity of interactions that agricultural research has found between rice production constraints.

Network graphs are also used as a visual tool. Since networks can become quite complex due to the number of actors and interactions which exist, the graphs are arranged using the Fruchterman-Reingold force-directed algorithm. An advantage of the Fruchterman-Reingold force-directed graph over geometric ones for representing a network is that the positioning of the actors in the graph depends on the interactions which exist, whereby interacting actors are located close to one another. The graph may therefore be seen as giving a crude indication of the centrality of each actor. Actors which interact with many other actors may be seen as clustering together whereas actors with few interactions should not be within close proximity to other actors.

\section{Results}

\section{Preliminary observations of time series data}

Figure 1 shows the number of journal articles cited by Scopus and published between 1997 and 2013 which were found to focus on at least one rice production constraint in South Asia. Figure 1 also shows the number of journal articles which focused on 'new' challenges, as described by [1]. It is clear that there has been a general increase in the number of publications per year during the observed period. However, the third time series in Figure 1, which represents the total number of agricultural and social science publications cited by Scopus related to South Asia, shows that there has been an increase in publications in general. Therefore, it could be argued that the increase in publications focused on production constraints is simply due to the general increase in publications. It is therefore difficult to determine from such a crude observation whether the food crisis in 2008 created a significant response in agricultural research in dealing with the food insecurity situation.

Figure 2 breaks down the number of journal articles focusing on production constraints into abiotic, biotic, management-related, and socio-economic constraints. One can observe that all four categories have been following an increasing trend, albeit at different magnitudes. Publications focusing on socio-economic constraints are lagging behind the other three categories while the category with the highest number of publications for each year between 1997 and 2013 was abiotic production constraints.

\section{De facto rice research priorities in South Asia}

The main motivation for this study was to attempt to reveal whether the focus of research relevant to South Asian agriculture, as identified by peer-reviewed journal articles, has been geared towards the most important production and non-production constraints of the most food-insecure South Asian smallholders. Table 1 displays the yield loss contribution of each production constraint, which is a weighted average of the four South Asian farming systems where rice makes up the largest area of land harvested. The yield losses for each of the four South Asian farming systems can be found in Additional file 1: Table S1. The weighted average takes into account the absolute number of stunted children residing in each farming system, which was taken from [33].

The table also indicates the number and percentage of journal articles which were found to primarily focus on each production constraint. An article was recorded as focusing on a particular production constraint if the production constraint keyword, as identified in Table 1, was included in the publication's title or as an indexed keyword. The last column gives the congruency ratios, which is the ratio between the percentage of relevant articles found and the weighted average yield loss. A tentative interpretation of a congruency ratio of more than 1 is that there is a surplus of research focusing on that particular production constraint whereas a ratio of less than 1 may suggest a deficit of research focusing on the particular production constraint.

Table 1 classifies the production constraints into four groups: socio-economic, abiotic, biotic, and managementrelated where each individual production constraint is ordered in descending order by its contribution to the total yield loss. The congruency ratios suggest that research related to socio-economic production constraints is severely lacking. The seven socio-economic constraints combined were the largest cause of South Asian rice yield losses, yet less than $8 \%$ of the research articles in the study's sample focused on at least one of the socio-economic constraints. The congruency ratios for irrigation and information access were 0 , since no articles focusing on these constraints 


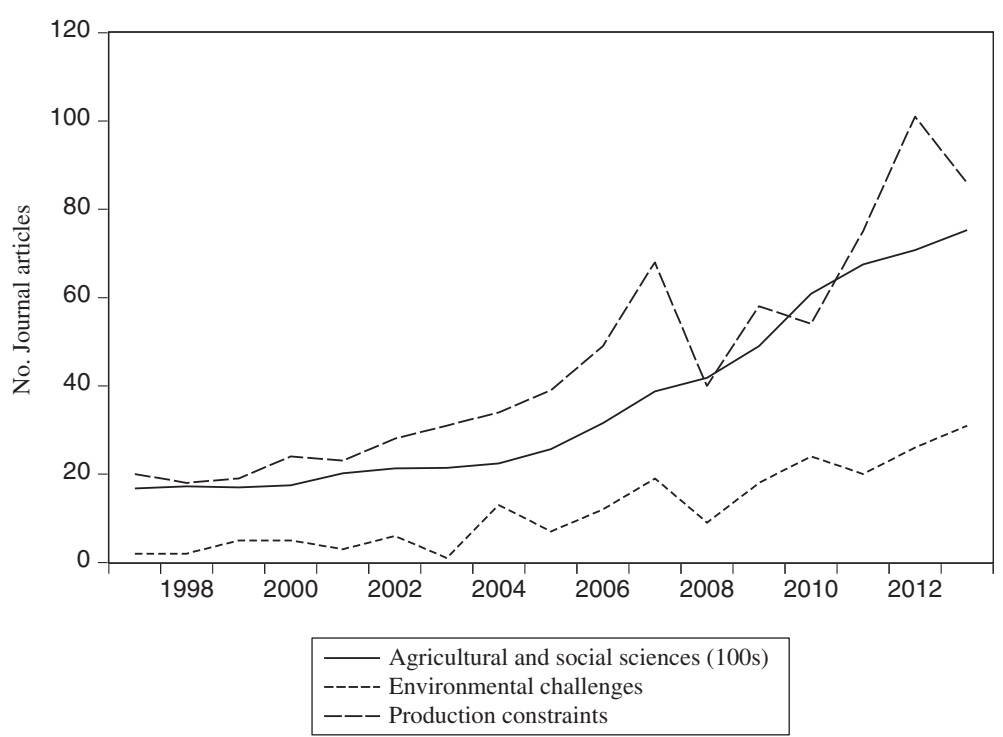

Figure 1 Journal articles cited by Scopus, 1997-2013.

were found in the Scopus search. The five remaining socio-economic constraints all had congruency ratios which scored well below 1 . Therefore, one may argue that research is lacking in all areas of socio-economic constraints affecting South Asian rice farmers.

On the opposite side of the scale, abiotic constraints were prioritized in $45 \%$ of the Scopus cited journal articles, even though this production constraints category represented less than $22 \%$ of total yield losses in foodinsecure South Asian farming systems. Abiotic constraints received by far the most attention in the literature. The three largest abiotic constraints-drought, soil fertility, and nitrogen, which make up a combined 15.7\% of the yield gap-were prioritized by $7.1 \%, 7.9 \%$, and $22.6 \%$ of the journal articles, respectively. Although abiotic constraints were the most numerous (11), five of them represent less than $1 \%$ of total rice yield losses. However, despite their relative unimportance to rice yield losses for the most food-insecure South Asian farming systems, some have arguably received a surplus of research attention. For instance, all five of these abiotic constraints had a congruency ratio of greater than 1 , while three of them scored higher than 5 . In fact, 10 of the 11 abiotic constraints had a congruency ratio greater than 1, suggesting that there may be an overemphasis on abiotic constraints research.

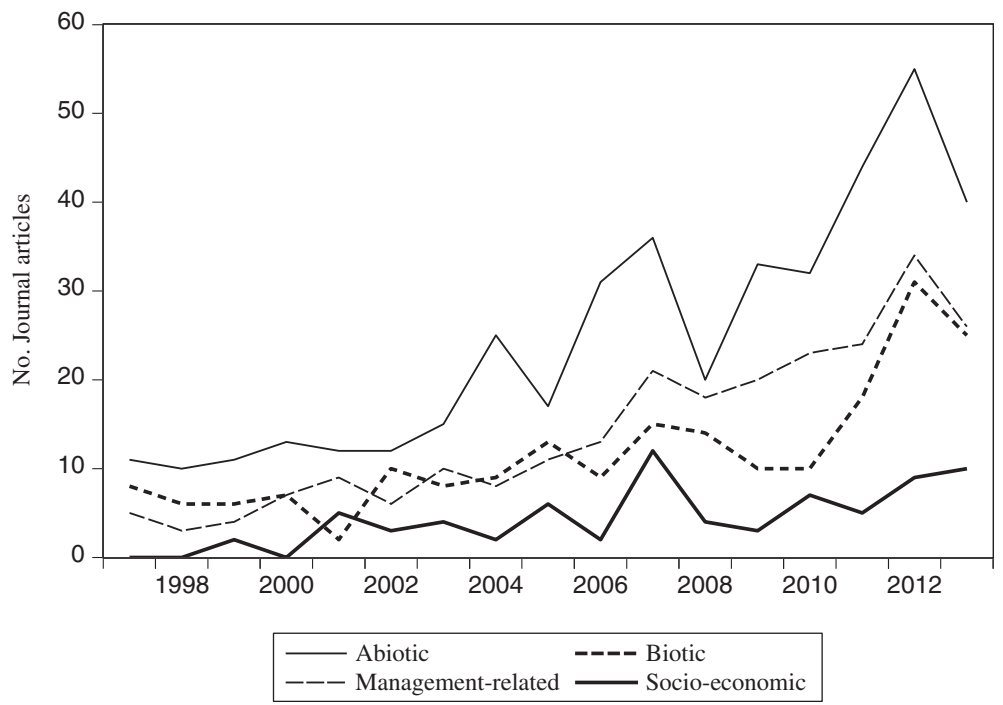

Figure 2 Journal articles cited by Scopus categorized into production constraints, 1997-2013. 
Table 1 Scopus cited journal articles prioritizing most important rice production constraints (1997-2014)

\begin{tabular}{|c|c|c|c|c|}
\hline \multirow[t]{2}{*}{ Major rice production constraints in South Asia } & \multirow{2}{*}{$\begin{array}{l}\text { Weighted average } \\
\text { yield loss \% }\end{array}$} & \multicolumn{2}{|c|}{ Relevant articles } & \multirow{2}{*}{$\begin{array}{c}\text { Congruency } \\
\text { ratios }\end{array}$} \\
\hline & & No. & $\%$ & \\
\hline Socio economic & 22.2 & 73 & 7.8 & 0.35 \\
\hline Difficult access to sufficient irrigation water & 4.5 & 0 & 0 & 0 \\
\hline Unavailability of quality seed & 3.8 & 15 & 1.6 & 0.42 \\
\hline High cost of irrigation & 3.4 & 20 & 2.1 & 0.63 \\
\hline Nitrogen fertilizer expensive/in short supply & 3.3 & 16 & 1.7 & 0.52 \\
\hline Inadequate farmer knowledge/training & 2.8 & 15 & 1.6 & 0.56 \\
\hline Insufficient access to agricultural information & 2.6 & 0 & 0 & 0 \\
\hline High price of inputs other than nitrogen & 2.1 & 10 & 1.1 & 0.50 \\
\hline Abiotic & 21.9 & 421 & 45.0 & 2.05 \\
\hline Drought or intermittent water stress & 6.9 & 66 & 7.1 & 1.03 \\
\hline Soil fertility depletion & 5.7 & 74 & 7.9 & 1.38 \\
\hline Nitrogen deficiency & 3.1 & 212 & 22.6 & 7.19 \\
\hline Flooding of low lying fields & 1.5 & 28 & 3.0 & 2.02 \\
\hline Deficiency or toxicity of micronutrients & 1.3 & 11 & 1.2 & 0.90 \\
\hline Phosphorus unavailability & 1.1 & 32 & 3.4 & 2.98 \\
\hline Cyclone/typhoon damage & 0.5 & 5 & 0.5 & 1.06 \\
\hline Soil physical/structural degradation & 0.5 & 27 & 2.9 & 5.76 \\
\hline High temperature stress & 0.4 & 20 & 2.1 & 6.07 \\
\hline Potassium deficiency & 0.4 & 10 & 1.1 & 3.03 \\
\hline Low temperature (cold) stress & 0.1 & 8 & 0.9 & 11.58 \\
\hline Biotic & 18.2 & 200 & 21.4 & 1.18 \\
\hline Weed competition & 6.6 & 85 & 9.1 & 1.38 \\
\hline Leaf and stem pests & 4.5 & 33 & 3.5 & 0.78 \\
\hline Leaf, stem, and panicle diseases & 3.4 & 75 & 8.0 & 2.35 \\
\hline Rodent damage & 1.8 & 6 & 0.6 & 0.35 \\
\hline Storage pests & 1.0 & 1 & 0.1 & 0.11 \\
\hline Root and soil diseases & 0.9 & 0 & 0 & 0 \\
\hline Soil insects & 0.5 & 2 & 0.2 & 0.44 \\
\hline Management-related & 21.5 & 244 & 26.1 & 1.21 \\
\hline Inadequate water management & 6.0 & 119 & 12.7 & 2.12 \\
\hline Inappropriate/poor nutrient/fertilizer use & 4.1 & 75 & 8.0 & 1.93 \\
\hline Late planting of crop & 2.7 & 20 & 2.1 & 0.80 \\
\hline Use of low yielding or old variety & 2.6 & 10 & 1.1 & 0.41 \\
\hline Poor crop rotations and sequences & 1.7 & 10 & 1.1 & 0.62 \\
\hline Inappropriate/poor insect/disease management & 1.6 & 14 & 1.5 & 0.92 \\
\hline Field crop establishment difficulties & 1.2 & 2 & 0.2 & 0.18 \\
\hline Inappropriate/poor weed management & 1.1 & 29 & 3.1 & 2.78 \\
\hline Poor seedling nursery management & 0.4 & 0 & 0 & 0 \\
\hline Total & 83.8 & 777 & 83.8 & \\
\hline
\end{tabular}

Note that the category totals are not necessarily the sum of the individual production constraints in each category. This is because some articles have focused on more than one production constraint.

Biotic production constraints combined make up the smallest contribution to total yield losses (18.2\%); however, some of the individual biotic constraints are substantial sources of yield losses. For instance, weeds are one of the largest single production constraints for South Asian rice cultivation, representing $6.6 \%$ of the yield gap. Researchers 
obviously recognize the importance of this constraint, as it has a congruency ratio of 1.38. The same could be said for leaf, stem, and panicle diseases such as blast and sheath blight, as this constraint scored a congruency ratio of 2.35 . However, the second greatest biotic constraint, leaf and stem pests, seems to have been overlooked. It represents $4.5 \%$ of total rice yield losses, yet it has a congruency ratio of 0.78 . Rodent damage is perhaps another area which demands further research attention, as it represents $1.8 \%$ of total rice yield losses, yet its congruency ratio was 0.35 . Furthermore, contrary to less severe abiotic constraints, less severe biotic constraints such as storage pests and soil diseases and insects received congruency ratios closer to 0 than 1 .

Management-related production constraints were prioritized by $26.1 \%$ of the journal articles in the sample and had a congruency ratio of 1.21 . It is important to note, however, that the bulk of research has focused on the two largest management constraints: water and fertilizer use. Seed varieties, planting, and crop rotation are three medium-sized management-related constraints which scored congruency ratios of less than 1 . The only medium-to-small management-related constraint to receive a surplus congruency ratio score was weed management. The others all had deficit scores.

According to the congruency ratios, several of the major rice production constraints affecting yields for the most vulnerable South Asian smallholders have been addressed by research. Two major exceptions to this are irrigation access and leaf and stem pests. However, [40] showed that smallholders are faced with a broad set of constraints which need to be considered collectively in order to increase yields. This argument is just as valid in the case of South Asian rice smallholders. What Table 1 shows is that there are a lot of small and medium socioeconomic, biotic, and management-related production constraints which, when combined, are at least as important as the sum of the most severe constraints. Despite this balance in yield loss contribution, the congruency ratios show there has been a significant imbalance in research focus.

\section{Linking production constraints in the research}

Degree centrality was calculated for the entire 1997-2014 period and the pre- and post-2008 periods. The links or interactions found between production constraints are illustrated in Figure 3, where each node represents a rice production constraint. The color of the nodes represents which type of production constraint it is, e.g., biotic is green. Moreover, the size of the node indicates how much the production constraint it represents contributes to total yield losses. In other words, the larger the node, the more significant is its contribution to yield losses. The width of the lines or edges connecting the nodes indicates how many research articles focused on both of those two particular production constraints.

Table 2 gives the degree of centrality for each of the production constraints and ranks the constraints. The constraints without a degree of centrality either had no journal articles focused on them, as already shown in Table 1, or have not been linked to any of the other rice production constraints by research articles.

Another objective of this study was to provide an insight into where research has linked different production constraints faced by South Asian rice farmers, to evaluate whether research is being conducted in isolation, or progress has been made in breaking down research silos. Degree centralities are used for this purpose. Over the entire 1997-2014 period, 28 of the production constraints were linked to at least one other production constraint by a research article. The most connected constraint was nitrogen; the least connected was rodents and soil insects.

As already seen in Table 1, three of the seven socioeconomic production constraints had not been considered by the Scopus cited literature. Of the four remaining socio-economic constraints which had been considered in the literature, all had been connected to other production constraints. Nitrogen supply had the highest degree of centrality, ranking sixth overall for the entire period. Cost of irrigation and farmer knowledge were jointly ranked ninth, while seed quality ranked 15 th for the entire period. However, comparing the centrality results for the pre- and post-2008 periods shows that these three socio-economic constraints have moved up in the overall ranking since 2008.

Five of the abiotic constraints were ranked among the ten most connected constraints. These included all four abiotic constraints which contributed to more than $1 \%$ of total rice yield losses. However, drought, which along with weeds, contributes the most to total yield losses overall, ranked lowest out of these five constraints. Interestingly, even some of the abiotic constraints, such as potassium and heat stress, which contributed less than $1 \%$ to total yield losses, were relatively well connected with other constraints, jointly ranking ninth for the entire period.

Weeds were the only biotic constraint which was relatively well connected in research articles. The other four biotic constraints, which had been linked in the literature to other constraints, ranked at the bottom, even though three of these constraints, namely (1) leaf and stem pests; (2) leaf, stem, and panicle diseases; and (3) rodents, collectively contribute roughly $10 \%$ of total rice yield losses for South Asian smallholders.

The two largest management-related production constraints, water management and fertilizer use, ranked in the top three most connected constraints for the entire 

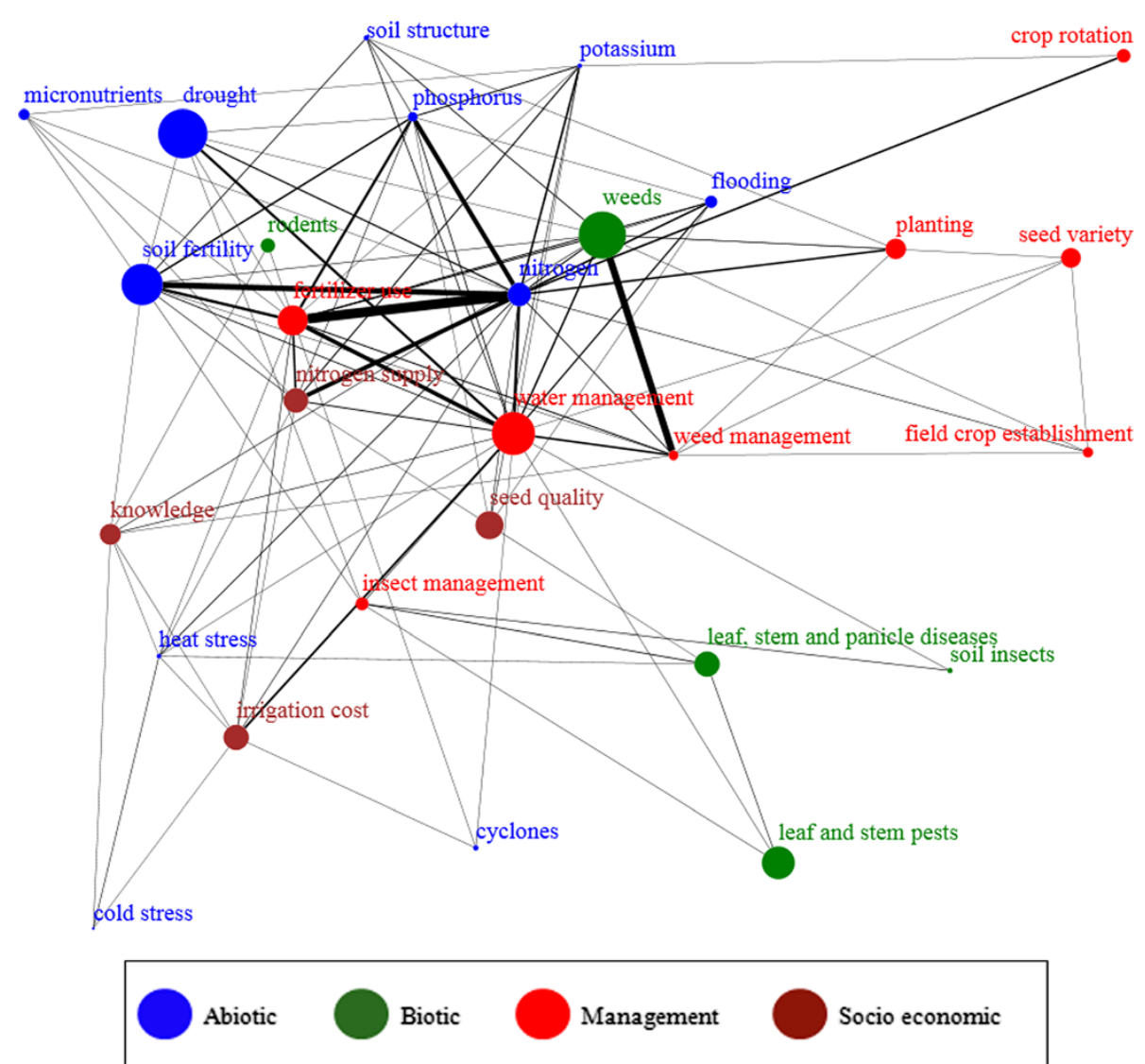

Figure 3 Network graph showing journal article interactions between rice production constraints in South Asia (1997-2014).

period. However, the next four most important management constraints (planting, seed varieties, crop rotation, and insect and disease management) did not rank very high, with three of them ranking near the bottom of the list despite the fact that the four combined make up a similar contribution to total yield losses as aggregated losses due to water management and fertilizer use.

Of the seven production constraints which contribute to $4 \%$ or more of the total yield losses, four ranked high in the degree of centrality, suggesting that research in a wide field of disciplines is considering these constraints. However, there have not been extensive links made for the major biotic constraint: leaf and stem pests. The medium-sized socio-economic and abiotic constraints, representing $2 \%-4 \%$ of yield losses, are positioned in the middle of the ranking. In contrast, the medium-sized biotic and managementrelated constraints ranked low, suggesting the disciplines that study them are relatively isolated from those focused on other major sources of rice production constraints for the most vulnerable South Asian smallholders.

\section{Linking production constraints with new challenges}

A second set of networks was specified which included the 'new' challenges discussed earlier. The rankings are not given since it does not seem sensible to compare production constraints with these non-production constraints, which should instead be seen as complementary to the former. Additional file 3: Figure S3 shows that for the entire period, the five environmental challenges-biodiversity, climate change, ecosystem services, natural resource management, and sustainability-as well as food security were relatively centrally located in the network. Comparing Additional file 3: Figure S4 and Additional file 3: Figure S5, which represent the pre- and post-2008 periods, respectively, shows how research has made significant progress in linking these 'new' challenges when considering rice production constraints in South Asia. One can observe how the nodes representing the five environmental challenges and food security have moved in substantially to the center of the network since 2008. This increase in linking these non-production challenges to other disciplines in the literature can also be seen by the degree of centrality results in Table 3 . The degree 
Table 2 Degree centrality results for rice production constraints

\begin{tabular}{|c|c|c|c|c|}
\hline \multirow[t]{2}{*}{ Rice production constraints in South Asia } & \multirow{2}{*}{$\begin{array}{c}\text { Yield losses } \\
\text { (weighted average) }\end{array}$} & \multicolumn{3}{|c|}{ Degree centrality (ranking in brackets) } \\
\hline & & 1997-2014 & 1997-2007 & 2008-2014 \\
\hline Socio economic & 22.2 & & & \\
\hline Difficult access to sufficient irrigation water & 4.5 & - & - & - \\
\hline Unavailability of quality seed & 3.8 & 6 (15th) & 3 (14th) & 5 (13th) \\
\hline High cost of irrigation & 3.4 & 8 (9th) & 3 (14th) & 8 (8th) \\
\hline Nitrogen fertilizer expensive/in short supply & 3.3 & 11 (6th) & 7 (6th) & 8 (8th) \\
\hline Inadequate farmer knowledge/training & 2.8 & 8 (9th) & 1 (22nd) & 8 (8th) \\
\hline Insufficient access to agricultural information & 2.6 & - & - & - \\
\hline High price of inputs other than $\mathrm{N}$ & 2.1 & - & - & - \\
\hline Abiotic & 21.9 & & & \\
\hline Drought or intermittent water stress & 6.9 & 7 (13th) & 3 (14th) & 6 (11th) \\
\hline Soil fertility depletion & 5.7 & 12 (4th) & 7 (6th) & $10(3 r d)$ \\
\hline Nitrogen deficiency & 3.1 & 18 (2nd) & $17(1 \mathrm{st})$ & $16(1 \mathrm{st})$ \\
\hline Flooding of low lying fields & 1.5 & 7 (13th) & 4 (9th) & 6 (11th) \\
\hline Deficiency or toxicity of micronutrients & 1.3 & 5 (17th) & 4 (9th) & 1 (25th) \\
\hline Phosphorus unavailability & 1.1 & 9 (7th) & 5 (8th) & 9 (6th) \\
\hline Cyclone/typhoon damage & 0.5 & $3(23 r d)$ & - & 3 (17th) \\
\hline Soil physical/structural degradation & 0.5 & 5 (17th) & 3 (14th) & 3 (17th) \\
\hline High temperature stress & 0.4 & 8 (9th) & 4 (9th) & 5 (13th) \\
\hline Potassium deficiency & 0.4 & 8 (9th) & 8 (4th) & 4 (16th) \\
\hline Low temperature (cold) stress & 0.1 & $3(23 r d)$ & - & 3 (17th) \\
\hline Biotic & 18.2 & & & \\
\hline Weed competition & 6.6 & 12 (4th) & 8 (4th) & $10(3 r d)$ \\
\hline Leaf and stem pests & 4.5 & $3(23 r d)$ & 2 (19th) & $2(23 r d)$ \\
\hline Leaf, stem, and panicle diseases & 3.4 & 4 (19th) & 4 (9th) & 3 (25th) \\
\hline Rodent damage & 1.8 & 2 (24th) & - & $2(23 r d)$ \\
\hline Storage pests & 1.0 & - & - & - \\
\hline Root and soil diseases & 0.9 & - & - & - \\
\hline Soil insects & 0.5 & 2 (24th) & - & $2(23 r d)$ \\
\hline Management-related & 21.5 & & & \\
\hline Inadequate water management & 6.0 & $19(1 s t)$ & $16(2 n d)$ & 15 (2nd) \\
\hline Inappropriate/poor nutrient/fertilizer use & 4.1 & $13(3 r d)$ & $12(3 r d)$ & $10(3 r d)$ \\
\hline Late planting of crop & 2.7 & 4 (19th) & 3 (14th) & 3 (17th) \\
\hline Use of low yielding or old variety & 2.6 & 4 (19th) & $1(22 n d)$ & 3 (17th) \\
\hline Poor crop rotations and sequences & 1.7 & 2 (24th) & 2 (19th) & 1 (25th) \\
\hline Inappropriate/poor insect/disease management & 1.6 & 6 (15th) & 2 (19th) & 5 (13th) \\
\hline Field crop establishment difficulties & 1.2 & 4 (19th) & 1 (22nd) & 3 (17th) \\
\hline Inappropriate/poor weed management & 1.1 & 9 (7th) & 4 (9th) & 9 (6th) \\
\hline Poor seedling nursery management & 0.4 & - & - & - \\
\hline
\end{tabular}

A dash (-) indicates that no interactions were made for that particular rice production constraint by the Scopus cited journal articles captured in the analysis. Rice production constraints with the same degree of centrality are given the same rank.

of centrality increased for all of the factors apart from diversification after 2008, and in fact, more than doubled in some instances.
Most frequent connections made by research

A feature of the network diagram in Figure 3 which has not been addressed yet is the width or thickness of the 
Table 3 Degree centrality results for new challenges

\begin{tabular}{lccc}
\hline New challenges & \multicolumn{3}{c}{ Degree centrality results } \\
\cline { 2 - 4 } & 1997-2014 & 1997-2007 & 2008-2014 \\
\hline Environmental challenges & 13 & 2 & 13 \\
Biodiversity & 10 & & 10 \\
Climate change & 24 & 15 & 19 \\
Ecosystems & 14 & 5 & 14 \\
Natural resource management & 15 & 5 & 14 \\
Sustainability & 8 & 4 & 5 \\
Crop diversification & 19 & 5 & 18 \\
Food security & & & \\
\hline
\end{tabular}

lines connecting the nodes. So far, we have discussed the degree or number of interactions that each constraint has. However, the frequency of interactions, that is to say, how many journal articles made a link between two particular constraints, also provides an insight into de facto research priorities. Figure 4 enlists the most common interactions identified by research among production constraints as well as between production and non-production constraints for each of the three time periods.

The constraints in Figure 4 are color-coordinated by their constraint type. The columns on the left display the most frequent interactions found between rice production constraints. The most common link made in the research was between nitrogen and fertilizer use, with 40 articles linking these two constraints between 1997 and 2014. It is clear that red and blue, that is, management- related and abiotic production constraints, rank as the most frequent interactions found in the literature. This is not surprising, since the results in Table 1 indicated that it was these two production constraint types which were shown to have been prioritized by journal articles. Another interesting point is that it tends to be the production constraints which ranked highest in terms of degree centrality that also have the highest frequency of journal articles linking them to other constraints. This pattern can also be seen in Figure 3, where the thickest lines tend to be connecting the production constraints which are the most centrally positioned in the network.

The interactions between production and non-production constraints, as shown on the right side of Figure 4, also tend to include these same abiotic and management-related production constraints. What this shows is that rice research relevant to South Asian smallholders tends to prioritize a relatively small group of abiotic and management-related production constraints, which can be seen not only in the diversity of links made in the research, as captured by the degree of centrality results, but also in the frequency of these interactions, as show in Figure 4.

\section{Discussion}

Smallholder farming has been at the top of the international community's agenda since the food crisis of 2007-2008, yet the resulting progress, as predicted by [18], has only been small. The need had been clearly defined, and funding is available, so why are there certain areas of production constraints that receive proportionally

\begin{tabular}{|c|c|c|c|c|c|c|c|c|c|c|c|}
\hline \multicolumn{6}{|c|}{ Rice production constraints interactions } & \multicolumn{6}{|c|}{ Rice production constraints interactions with new challenges } \\
\hline 1997-2014 & No. & 1997-2007 & No. & 2008-2014 & No. & $1997-2014$ & No. & 1997-2007 & No. & 2008-2014 & No. \\
\hline $\begin{array}{l}\text { Fertilizer use - } \\
\text { Nitrogen }\end{array}$ & 40 & $\begin{array}{l}\text { Fertilizer use - } \\
\text { Nitrogen }\end{array}$ & 16 & $\begin{array}{l}\text { Nitrogen - Fertilizer } \\
\text { use }\end{array}$ & 24 & $\begin{array}{l}\text { Ecosystems - } \\
\text { nitrogen }\end{array}$ & 9 & $\begin{array}{l}\text { Ecosystems - } \\
\text { Weeds }\end{array}$ & 5 & $\begin{array}{l}\text { Nitrogen - } \\
\text { Ecosystems }\end{array}$ & 7 \\
\hline $\begin{array}{l}\text { Weed } \\
\text { management - } \\
\text { Weeds }\end{array}$ & 28 & $\begin{array}{l}\text { Nitrogen - Soil } \\
\text { fertility }\end{array}$ & 9 & $\begin{array}{l}\text { Weeds - Weed } \\
\text { management }\end{array}$ & 21 & $\begin{array}{l}\text { Sustainability - } \\
\text { Water management }\end{array}$ & 8 & $\begin{array}{l}\text { Natural resource } \\
\text { management - } \\
\text { water management }\end{array}$ & 4 & $\begin{array}{l}\text { Drought - } \\
\text { Ecosystems }\end{array}$ & 5 \\
\hline $\begin{array}{l}\text { Nitrogen - Soil } \\
\text { fertility }\end{array}$ & 22 & $\begin{array}{l}\text { Fertilizer use - } \\
\text { Water } \\
\text { management }\end{array}$ & 8 & $\begin{array}{l}\text { Nitrogen - Soil } \\
\text { fertility }\end{array}$ & 13 & $\begin{array}{l}\text { Ecosystems - } \\
\text { Weeds }\end{array}$ & 7 & $\begin{array}{l}\text { Sustainability - } \\
\text { Water management }\end{array}$ & 4 & $\begin{array}{l}\text { Soil fertility - } \\
\text { Sustainability }\end{array}$ & 4 \\
\hline $\begin{array}{l}\text { Nitrogen - } \\
\text { Phosphorus }\end{array}$ & 18 & $\begin{array}{l}\text { Nitrogen - } \\
\text { Phosphorus }\end{array}$ & 8 & $\begin{array}{l}\text { Nitrogen - Nitrogen } \\
\text { supply }\end{array}$ & 10 & $\begin{array}{l}\text { Nitrogen - } \\
\text { Sustainability }\end{array}$ & 7 & $\begin{array}{l}\text { Nitrogen - } \\
\text { Sustainability }\end{array}$ & 3 & $\begin{array}{l}\text { Drought - Food } \\
\text { security }\end{array}$ & 4 \\
\hline $\begin{array}{l}\text { Nitrogen - } \\
\text { Nitrogen supply }\end{array}$ & 17 & $\begin{array}{l}\text { Nitrogen - } \\
\text { Nitrogen supply }\end{array}$ & 7 & $\begin{array}{l}\text { Nitrogen - } \\
\text { Phosphorus }\end{array}$ & 10 & $\begin{array}{l}\text { Drought - } \\
\text { Ecosystems }\end{array}$ & 6 & $\begin{array}{l}\text { Diversification - } \\
\text { soil fertility }\end{array}$ & 2 & $\begin{array}{l}\text { Water } \\
\text { management - } \\
\text { sustainability }\end{array}$ & 4 \\
\hline $\begin{array}{l}\text { Fertilizer use - } \\
\text { Water } \\
\text { management }\end{array}$ & 16 & $\begin{array}{l}\text { Weeds - Weed } \\
\text { management }\end{array}$ & 7 & $\begin{array}{l}\text { Drought - Water } \\
\text { management }\end{array}$ & 9 & $\begin{array}{l}\text { Natural resource } \\
\text { management - } \\
\text { Water management }\end{array}$ & 6 & $\begin{array}{l}\text { Ecosystems - } \\
\text { Water management }\end{array}$ & 2 & $\begin{array}{l}\text { Nitrogen - } \\
\text { sustainability }\end{array}$ & 4 \\
\hline $\begin{array}{l}\text { Fertilizer use - } \\
\text { Soil fertility }\end{array}$ & 11 & $\begin{array}{l}\text { Nitrogen - } \\
\text { Potassium }\end{array}$ & 5 & $\begin{array}{l}\text { Fertilizer use - Water } \\
\text { management }\end{array}$ & 8 & $\begin{array}{l}\text { Soil fertility - } \\
\text { Sustainability }\end{array}$ & 6 & $\begin{array}{l}\text { Ecosystems - } \\
\text { Nitrogen }\end{array}$ & 2 & $\begin{array}{l}\text { Phosphorus - } \\
\text { food security }\end{array}$ & 3 \\
\hline $\begin{array}{l}\text { Nitrogen - Water } \\
\text { management }\end{array}$ & 11 & $\begin{array}{l}\text { Nitrogen - Water } \\
\text { management }\end{array}$ & 5 & $\begin{array}{l}\text { Soil fertility - } \\
\text { Fertilizer use }\end{array}$ & 7 & $\begin{array}{l}\text { Drought - Food } \\
\text { security }\end{array}$ & 4 & $\begin{array}{l}\text { Fertilizer use - } \\
\text { sustainability }\end{array}$ & 2 & $\begin{array}{l}\text { Fertilizer use - } \\
\text { ecosystems }\end{array}$ & 3 \\
\hline $\begin{array}{l}\text { Fertilizer use - } \\
\text { Phosphorus }\end{array}$ & 10 & $\begin{array}{l}\text { Fertilizer use - } \\
\text { Nitrogen supply }\end{array}$ & 4 & $\begin{array}{l}\text { Fertilizer use - } \\
\text { Phosphorus }\end{array}$ & 7 & $\begin{array}{l}\text { Ecosystems - } \\
\text { Water management }\end{array}$ & 4 & $\begin{array}{l}\text { Soil fertility - } \\
\text { sustainability }\end{array}$ & 2 & $\begin{array}{l}\text { Nitrogen - food } \\
\text { security }\end{array}$ & 3 \\
\hline $\begin{array}{l}\text { Drought - Water } \\
\text { management }\end{array}$ & 10 & $\begin{array}{l}\text { Fertilizer use - } \\
\text { Soil fertility }\end{array}$ & 4 & $\begin{array}{l}\text { Nitrogen - Water } \\
\text { management }\end{array}$ & 6 & & & & & & \\
\hline & & $\begin{array}{l}\text { Flooding - } \\
\text { Nitrogen }\end{array}$ & 4 & $\begin{array}{l}\text { Water management - } \\
\text { Weed management }\end{array}$ & 6 & & & & & & \\
\hline Abiotic & & 6 & an & Socioecon & & imental & & d security & & ation & \\
\hline
\end{tabular}


little research attention? GAFSP and CGIAR have been primed to strategically invest in key areas of agricultural research, and have shown that the progress made against poverty and malnutrition with even small improvements in agricultural efficiency are worthwhile and significant. For instance, a $1 \%$ increase in agricultural production is expected to lead to a five times larger increase in poverty reduction than a 1\% increase in GDP [43]. Since agricultural improvements for smallholders are seen as so effective in meeting international poverty and food security goals, why are there so many areas of potential yield gains which are not being addressed by peer-reviewed research? For instance, in the case of South Asian rice productivity, socioeconomic production constraints, which make up over $22 \%$ of the entire yield losses, could be the source of new increases in yields if research priorities are re-evaluated to consider this neglected research area.

\section{Obsession with yields}

Commitments made at the World Food Summit in 1996 and in MDG 1.C have not been fully realized. The proportion of undernourished people has declined globally, but this average ignores substantial variation across regions. Agricultural research in South Asia has largely focused on yield-enhancing technologies for rice and wheat that have been successful at meeting countries' food production goals [32]. Yet these yield increases must be seen in context. This area is one of the most drought-prone and foodinsecure areas in the world. Within the dominant ricewheat and rainfed mixed farming system areas, there are 28.3 and 24.5 million stunted children, respectively. In fact, five of the top ten farming systems with the most recorded stunting were in South Asia. Clearly, an overt focus on yield has gotten results, but whom do these results benefit? How much do they contribute to reducing stunting and poor nutrition within the region?

Of course, yield is in itself a broad term, and there are several constraints that contribute to yield losses. However, this study has highlighted the fact that research tends to prioritize certain types of production constraints, overlooking other constraints which collectively are substantial contributors to total yield losses, such as socio-economic, biotic, and management-related constraints.

This study has shown that while there is relatively 'lowhanging fruit' awaiting research $-7 \%$ of articles reviewed focusing on socio-economic constraints which account for $22 \%$ of the yield gap-there is no system in place to direct high-quality academic research into areas where the results would have maximum impact in terms of addressing the food security concerns of some of the world's largest malnourished population. So while individual factors such as nitrogen deficiency have a significant impact on production (and are especially relevant within intensive, commercial farming), the gains to be made from further study are dwarfed by those to be made through research into other lesser-known constraints that have a proportionately larger impact.

\section{Communications}

The central finding of this study is that there is a disconnect between the types of research that are prioritized and funded in peer-reviewed academic research at many universities and research institutes, and the types of information needed to address 'real-world' problems. Of course, these are not mutually exclusive, but the findings of this study suggest that there are known areas of research that receive very little attention but which can have a proportionally larger impact. This disconnect can be seen between the stated commitments made at events such as the World Food Summit in 1996, and within the MDGs, and the de facto prioritization of research within academia.

The disconnect manifests itself through a lack of communication of information needs from the implementation side and a lack of communication and knowledgebrokering between research-generating institutions and research users. Newer sources of funding such as the Bill \& Melinda Gates Foundation and the Yara Foundation have led to a shortcutting of the peer-review system, directly taking research knowledge to implementation. However, it remains to be seen whether these institutions have gone too far in ignoring the benefits of contributing to journal submissions for the peer-reviewed system.

It should be in the interest of research institutions in South Asia, particularly the NARS, to address this disconnect. For instance, ICAR explicitly states that supporting smallholder agriculture and sustainably managing natural resources goes hand in hand. However, the network analysis conducted in this study suggests that research has not yet begun to build bridges between many of the production constraints and these new environmental challenges.

\section{Conclusions}

This study was motivated by the growing commitments in international and national agendas to reduce poverty and increase the status of the food security situation of the most vulnerable groups in the world through supporting smallholder agriculture. Its aim was to determine whether academic research was focusing on the greatest causes of yield losses in the most food-insecure farming systems in South Asia. It also sought to determine whether research was considering environmental constraints that the international community (IPCC, FAO, IFAD) identifies as new challenges for smallholders (such as climate change). The study searched for relevant journal articles cited by Scopus and used yield loss estimates from the literature to calculate congruency ratios. These ratios were then interpreted to determine where there had been a surplus or deficit in agricultural 
research for South Asian rice farmers who make up a sizable section of the world's most food-insecure. Degree centralities were also estimated to see which different types of rice constraints had been linked together by journal articles.

The results suggest that while research had focused on several of the most severe production constraints, many medium-sized and large constraints have not received the warranted research attention. The most striking finding was the shortage of research focused on socioeconomic production constraints, despite that being the most important category of production constraints to South Asian rice farmers in terms of contributing to yield losses. An implication of the study is that if international and national development organizations want research to better support smallholder agriculture, research on overlooked and underfunded production constraints will need to be addressed through better coordination between research organizations and the institutions that fund the research. The paper's findings highlight specific areas which perhaps deserve more attention from agricultural research in light of their relative importance to current rice yield losses for South Asian smallholders.

It is important to highlight the methodological limitations of the study. While there are weaknesses in the way the journal articles were quantified, there are also issues with the quality of research in terms of its usefulness to smallholder farmers. The international community and researchers are beginning to recognize that the way they conduct their research significantly affects technology adoption by farmers. A high-level panel [1] argued that the way research is conducted needs to be participatory and empowering for smallholders. Moreover, to achieve this, research systems need to be held accountable to smallholders, whereby their funding depends on the impact of their research. This study has not considered the quality of peer-reviewed research in this respect, but such an analysis would no doubt improve our understanding of how effective research has been in dealing with the production and environmental constraints that smallholder face.

Such a change in how research is conducted is also recognized by NARS such as ICAR, which has set the promotion of farmer-participatory research as a priority in its mission statement. In fact, in the case of India, the problems raised in this study, such as a lack of research from the social sciences and understanding the relevance of natural resource management to agricultural production seem to be well understood since those topics are clearly identified among South Asian agricultural research priorities.

What is also clear from the results of this study, however, is that there is a large gap between official and de facto research priorities. In defense of the research community, it is understandable that there is a path dependency, where research tends to be pursued in areas which complement South Asia's research resource base-for instance, pursing abiotic rather than socio-economic research. This tradition derives from a legacy of viewing agricultural production constraints as being within the realm of the natural sciences which explains why agricultural departments in universities and research institutions are set up to deal with abiotic constraints in great detail. In contrast, when it comes to the socio-economic production constraints, as these draw heavily on the social sciences, there are simply not the personnel within these departments to tackle these issues in the same depth. Therefore, if the under-researched priority areas are to be addressed in a meaningful way, institutional transformations in South Asia's agricultural research institutions are needed. Furthermore, funding and donor institutions and governments have a critical role in supporting the research organizations to ensure that these research gaps-as have been shown in this paper-are addressed.

One crucial role for organizations which fund South Asian agricultural research lies within the assessment of the impact of their research investments, and this is already happening to a large extent. Hazell [32] argues that the returns from South Asian agricultural research investments in terms of productivity are widely studied in the literature. However, he goes on to point out that the same cannot be said for impact assessment in terms of poverty reduction, which is surprising since poverty reduction tends to be one of the key drivers behind justifying funds for agricultural research. Donors therefore also have their role to play in monitoring funded research in order to increase the level of accountability of agricultural research organizations for their research output and impact on poverty and food security.

Ending on a positive note, with the emergence of crosscutting topics such as food security, it has become easier to justify collaborations across traditional academic divisions, especially, as we have shown in this paper, given the fact that the different academic fields tend to have an equal standing in importance in terms of reducing rice production losses.

\section{Additional files}

Additional file 1: Table S1. Operationalizing production constraints for Scopus queries and Table S2. yield losses for South Asian farming systems. Additional file 2: Dataset used in the analysis taken from the Scopus queries.

Additional file 3: Additional network diagrams. Figure S1. Network graph showing journal article interactions for rice production constraints in South Asia, 1997-2007. Figure S2. Network graph showing journal article interactions for rice production constraints in South Asia, 2008-2014.

Figure S3. Network graph showing journal article interactions for rice production constraints and new challenges in South Asia, 1997-2014. Figure S4. Network graph showing journal article interactions for rice 
production constraints and new challenges in South Asia, 1997-2007. Figure S5. Network graph showing journal article interactions for rice production constraints and new challenges in South Asia, 2008-2014.

\begin{abstract}
Abbreviations
APAARI: Asia-Pacific Association of Agricultural Research Institutions; CGIAR: Consultative Group on International Agricultural Research; CIMMYT: International Maize and Wheat Improvement Center; FAO: Food and Agricultural Organization; GAFSP: Global Agriculture and Food Security Program; GDP: gross domestic product; IARC: international agricultural research centers; ICAR: Indian Centre of Agricultural Research; IFAD: International Fund for Agricultural Development; IFPRI: International Food Policy Research Institute; IPCC: Intergovernmental Panel on Climate Change; IRRI: International Rice Research Institute; LFA: Least Favorable Areas; MDG: Millennium development goals; NARS: National Agricultural Research Systems; UN: United Nations.
\end{abstract}

\section{Competing interests}

The authors declare that they have no competing interests.

\section{Authors' contributions}

Both authors were involved in the conception of the idea and design of the study. AJ collected and analyzed the data. Both authors interpreted the data and drafted, read, and approved the final manuscript.

\section{Acknowledgements}

We would like to thank Dr. Louise Karlberg for providing useful suggestions during the conception of this article, Drs. Stephen Waddington and Li Xiaoyun for the data they shared with us, and Marion Davis for reviewing an earlier draft. We would also like to thank the anonymous reviewer and editors of the journal for their input. SIANI (the Swedish International Agricultural Network Initiative) provided the publication fees for the article which we are sincerely grateful for. Naturally, the authors take full responsibility for the content of the article.

\section{Author details}

${ }^{1}$ Institute of Agricultural and Food Policy Studies, Universiti Putra Malaysia, Putra Infoport, Jalan Kajang-Puchong, Serdang, Selangor 43400, Malaysia. ${ }^{2}$ Stockholm Environment Institute, Linnégatan 87 D, Stockholm 115 23, Sweden. ${ }^{3}$ Swedish International Agricultural Network Initiative (SIANI), Linnégatan 87 D, Stockholm 115 23, Sweden.

\section{Received: 17 June 2014 Accepted: 8 October 2014}

Published: 3 December 2014

\section{References}

1. HLPE: Investing in smallholder agriculture for food security. In A report by the High Level Panel of Experts on Food Security and Nutrition of the Committee on World Food Security, Rome; 2013.

2. CGIAR: Changing Agricultural Research in a Changing World. A Strategy and Results Framework for the Reformed CGIAR. Montpellier: Consultative Group on International Agricultural Research; 2013.

3. IFAD: IFAD Strategic Framework 2011-2015. Rome: International Fund for Agricultural Development; 2011.

4. FAO: Biotechnologies at Work for Smallholders: Case Studies from Developing Countries in Crops, livestock and Fish. Rome: Food and Agricultural Organization; 2013.

5. IFAD: Smallholders, Food Security and the Environment. Rome: International Fund for Agricultural Development; 2013.

6. APAARI and IFPRI: Priorities for Agricultural Research for Development in South Asia; 2013

7. ICAR: Vision 2030. New Delhi: Indian Council of Agricultural Research; 2011.

8. World Bank, FAO, and IFAD: Gender in Agriculture Sourcebook. Washington, DC: World Bank, Food and Agricultural Organization, and International Fund for Agricultural Development; 2009.

9. Koohafkan P: Globally Important Agricultural Heritage Systems. Beijing: Presentation at the International Forum on Globally Important Agricultural Heritage Systems (GIAHS); 2011:9-11.
10. IAASTD: Agriculture at a Crossroads: Sub-Saharan Africa (SSA) Report (Vol. V). Washington, DC: International Assessment of Agricultural Knowledge, Science and Technology for Development, Island Press; 2009.

11. IFAD: Viewpoint: Smallholders Can Feed the World. Rome: International Fund for Agricultural Development; 2011.

12. UN: The Millennium Development Goals Report, United Nations New York; 2013.

13. Millennium Project UN: Halving hunger: It can be done. Task Force on Hunger. London, Sterling, VA, USA: Earthscan; 2005.

14. GAFSP: Framework Document for a Global Agriculture and Food Security Program; 2009. Sustainable Development Network; 2009. The World Bank: Washington, D. C.

15. IFAD: Rural Groups and the Commercialization of Smallholder Farming: Targeting and Development Strategies (draft). (Issues and Perspectives from a Review of IOE Evaluation Reports and Recent IFAD country Strategies and project Designs). Rome: International Fund for Agricultural Development; 2011

16. FAO: The State of Food and Agriculture, Investing in Agriculture. Rome: Food and Agricultural Organization; 2012

17. Lipton M: The Family Farm in a Globalizing World: the Role of Crop Science in Alleviating Poverty. Washington, D.C: International Food Policy Research Institute (IFPRI); 2005

18. Dixon J, Gulliver A, Gibbon D: Farming Systems and Poverty. Improving Farmers' Livelihoods in a Changing World. Rome and Washington DC: Food and Agricultural Organization and World Bank; 2001.

19. Crowley E: Ending Poverty: Learning from Good Practices of Small and Marginal Farmers. Rome: Self Employed Women's Association Exposure and Dialogue and the Food and Agricultural Organization; 2013.

20. Hasan R, Quibria MG: Industry matters for poverty: a critique of agricultural fundamentalism. Kyklos 2004, 57:253-264.

21. Ellis F: Small farms, Livelihood Diversification, and Rural-Urban Transitions: Strategic Issues in Sub-Saharan Africa. Washington: International Food Policy Research Institute; 2005.

22. Cline WR: Global Warming and Agriculture: Impact Estimates by Country. Washington, D.C: Peterson Institute; 2007.

23. Gornall J, Betts R, Burke E, Clark R, Camp J, Willett K, Wiltshire A: Implications of climate change for agricultural productivity in the early twenty-first century. Philos Trans R Soc Lond B Biol Sci 2010, 365:2973-2989.

24. HLTF: High Level Task Force on the Global Food Security Crisis. Outcomes and Action for Global Food Security. New York, USA: Excerpts from the Comprehensive Framework for Action; 2008.

25. HLPE: Food Security and Climate Change. Rome: A report by the High Level Panel of Experts on Food Security and Nutrition of the Committee of World Food Security; 2012.

26. FAO: The State of Food and Agriculture (SOFA): Food Systems for Better Nutrition. Rome: Food and Agricultural Organization; 2013.

27. FAO: Agriculture, Food and Nutrition for Africa: A Resource Book for Teachers of Agriculture. Rome: Food and Agricultural Organization; 1997.

28. Thornton PK, Jones PG, Alagarswamy G, Anderson J: Spatial variation of crop yield response to climate change in East Africa. Glob Environ Change 2009, 19:54-65.

29. Sultan B, Roudier P, Quirion P, Alhassane A, Muller B, Dingkuhn M, Ciais P, Guimberteau M, Traore S, Baron C: Assessing climate change impacts on sorghum and millet yields in the Sudanian and Sahelian savannahs of West Africa. Environ Res Lett 2013, 8(1).

30. Evenson R, Gollin D: Contributions of national agricultural research systems to crop productivity. In Handbook of Agricultural Economics. 3rd edition. Edited by Evenson R, Pingali P; 2007:2420-2447.

31. Garg KC, Kumar S, Lal K: Scientometric profile of Indian agricultural research as seen through science citation index expanded. Scientometrics 2006, 68(1):151-166.

32. Hazell PBR: An Assessment of the Impact of Agricultural Research in South Asia since the Green Revolution. Rome, Italy: Science Council Secretariat; 2008.

33. Hyman G, Fujisaka S, Jones P, Wood S, De Vicente MC, Dixon J: Strategic approaches to targeting technology generation: Assessing the coincidence of poverty and drought-prone crop production. Agric Syst 2008, 98(1):50-61.

34. Gibbon D, Dixon J, Flores D: Beyond Drought Tolerant Maize: Study of Additional Priorities in Maize. Report to Generation Challenge Program. Mexico DF, Mexico: CIMMYT; 2007:42.

35. Waddington SR, Li X, Dixon J, Hyman G, De Vicente MC: Getting the focus right: production constraints for six major food crops in Asian and African farming systems. Food Secur 2010, 2(1):27-48. 
36. Pouris A, Pouris A: The state of science and technology in Africa (2000-2004): a scientometric assessment. Scientometrics 2009, 79(2):297-309.

37. Hassan S, Haddaway P, Kuinkel P, Degelsegger A, Blasy C: A bibliometric study of research activity in ASEAN related to the EU in FP7 priority areas. Scientometrics 2012, 91:1035-1051.

38. Kosecki S, Shoemaker R, Baer CK: Scope, characteristics, and use of the U. S. Department of Agriculture's intramural research. Scientometrics 2011, 88:707-728.

39. Stads G, Roozitalab MH, Beintema NM, Aghajani M: Agricultural research in Iran. Policy, investments, and institutional reform. In ASTI country report. Washington, D. C: International Food Policy Research Institute (IFPRI) and Agricultural Extension, Education and Research Organization (AEERO); 2008.

40. Newman MEJ: Networks: An Introduction. Oxford, UK: Oxford University Press; 2010

41. Zuo M, Hua X, Wen X: Who is the best connected researcher? An analysis of co-authorship networks of knowledge management from 2000 to 2010. In The 19th International Conference on Industrial Engineering and Engineering Management. Edited by Ershi Qi, Jian Sheng, Runliang Dou; 2013:761-770

42. Newman MEJ: A measure of betweenness centrality based on random walks. Soc Netw 2005, 27:39-54

43. Christiaensen L, Demery L, Kuhl J: The (evolving) role of agriculture in poverty reduction - an empirical perspective. J Dev Econ 2011, 96:239-254.

doi:10.1186/2048-7010-3-18

Cite this article as: John and Fielding: Rice production constraints and 'new' challenges for South Asian smallholders: insights into de facto research priorities. Agriculture \& Food Security 2014 3:18.

\section{Submit your next manuscript to BioMed Central and take full advantage of:}

- Convenient online submission

- Thorough peer review

- No space constraints or color figure charges

- Immediate publication on acceptance

- Inclusion in PubMed, CAS, Scopus and Google Scholar

- Research which is freely available for redistribution 